\title{
Surgical treatment of synovial-collagen disorders of the hand
}

\author{
H. Kirk Watson ${ }^{1}$, Purnell Traverso', Lois Carlson ${ }^{1}$, Daniel Mastella1, Ronit Wollstein ${ }^{2,3}$ \\ ${ }^{1}$ Department of Orthopedic Surgery, Division of Hand and Upper Extremity Surgery, The Hand Center, Glastonbury, CT 06033, USA. \\ ${ }^{2}$ Department of Orthopedic Surgery, The Technion School of Medicine, Haifa 31096, Israel. \\ ${ }^{3}$ Department of Plastic Surgery, University of Pittsburgh Medical School, Pittsburgh, PA 15261, USA.
}

Address for correspondence: Prof. Ronit Wollstein, 3550 Terrace Street, Pittsburgh, PA 15261, USA. E-mail: ronitwollstein@gmail.com

\begin{abstract}
Critical relationships between collagen and synovium exist and affect the function of the hand. Understanding these relationships enhances the ability to perform surgery including procedures addressing soft tissue and joint pathology. We present a series of surgical procedures based on this principle.
\end{abstract}

Key words:

Collagen, hand, plastic, surgery, synovium

\section{INTRODUCTION}

The practice of hand surgery requires an understanding of the anatomy, the intimate relationships between collagen and synovium, and the ultimate function of the hand. This is critical to the performance of surgery ranging from skin coverage following a crush injury to tendon or toe transfers in congenital hand cases. We present a series of surgical procedures based on this understanding.

Pathologic conditions resulting in synovial irritation or inflammation involve an array of molecular pathways, which can lead to the pathologic deposition of collagen in the hand and wrist. Chronically inflamed synovium will thicken adjacent collagen and create these phenomena (the "collasyn theory"). In the hand, collagen and synovial tissue are anatomically closely associated. The support structures, mostly made up of collagen (bones, tendons, ligaments), are lined with synovial tissue in areas where tissue motion requires a reduction in the coefficient of friction.

Surgical procedures must address the inflamed synovium, which, by virtue of its close anatomic proximity,

\begin{tabular}{|l|l|}
\hline \multicolumn{2}{|c|}{ Access this article online } \\
\hline Quick Response Code: & Website: \\
\hline & www.parjournal.net \\
\hline & \\
\hline & Dol: \\
\hline & $10.4103 / 2347-9264.153192$ \\
\hline
\end{tabular}

"communicates" with the adjacent collagen structures and may cause collagen thickening and multiple symptomatic changes. Surgery may be needed to: (1) remove inflamed synovium; (2) increase space around affected structures and (3) remove abnormal tissues (such as osteophytes) that occur secondary to the effects of the inflamed synovium on adjacent collagen structures. This surgical approach decreases symptoms and may enhance joint longevity.

\section{SURGICAL SERIES}

\section{Rheumatoid arthritis}

The deformities in the hand in rheumatoid arthritis often follow a predictable pattern. The formula is destructive synovitis plus load equals deformity. If viewed through the lens of the collasyn theory, synovitis will rupture tendons at the distal edge (load area) of the extensor retinaculum. Synovitis also stimulates protective over-activity of the intrinsics, creating abnormal loads in the fingers. These loads most often create pressure on the dorsoradial capsule and ligaments of the metacarpophalangeal (MP) joint resulting in volar and ulnar subluxation of the proximal phalanx. If there is insufficient synovitis in the MP joint, the MP joints will not subluxate. The intrinsic loads then are transmitted to the fingers, resulting in swan necks, boutonnieres, dislocations or even interphalangeal fusion. Applying this concept allows prediction of expected deformity on clinical examination. Tight intrinsics (positive Bunnell test) should be released early, removing the load component of the destructive formula. The ulnar drift and deformities of the wrist are the result 
of the "downslope" loads created by the anatomy of the articular surface of the distal radius.

\section{Stenosing tenosynovitis or trigger finger}

The effects of the interaction between synovium and collagen can be seen in trigger fingers. In stenosing tenosynovitis of the finger flexors, there is a thickened retinaculum or pulley that constricts the osseofibrous tunnel through which the tendon runs. ${ }^{[1]}$ Chronic synovial irritation affects collagen deposition in the A1 pulley and leads to a progressive thickening and sometimes metaplasia of the pulley ${ }^{[1-3]}$ [Figure 1]. During sleep, edema collects in the tendon proximal and distal to the pulley. The symptomatic sequelae include stiffness in the mornings as patients open and close their fingers to "milk" the fluid back into the natural shape of the tendons, or "locking" of the fingers if a nodule is too big to pass through the pulley. Conservative treatment may include steroid injections, splinting and activity modification. If this fail, surgery is indicated. ${ }^{[4]} \mathrm{A}$ release of the A1 pulley increases space to allow normal tendon gliding. Surgery has been shown to be more successful in the absence of diabetes. ${ }^{[5]}$

The collasyn theory explains why there is an increased incidence of stenosing tenosynovitis (trigger finger) in the thumb and little finger following carpal tunnel surgery. Infection can move from thumb to little finger through the common synovial lining between the thumb, the carpal tunnel and the fibro-osseous sheath of the little finger flexors. Surgery on the carpal tunnel produces inflammation of this communicating synovium, which then has its hypertrophic effect on the collagen of the A1 pulleys.

\section{Fourth extensor compartment synovitis}

Collasyn pathology is also seen in the extensor retinaculum. Patients with fourth extensor compartment stenosing tenosynovitis develop a thickened retinaculum. In performing ultrasound evaluation, Zhou et al. ${ }^{[6]}$ found that with increased extension of the wrist, the contact area between the extensor retinaculum and the extensor tendons decreased, causing increased friction. We have found that a release of the septa between the fourth and fifth extensor compartments without releasing the external retinaculum is all that is needed to provide sufficient room for the tendons. ${ }^{[7]}$

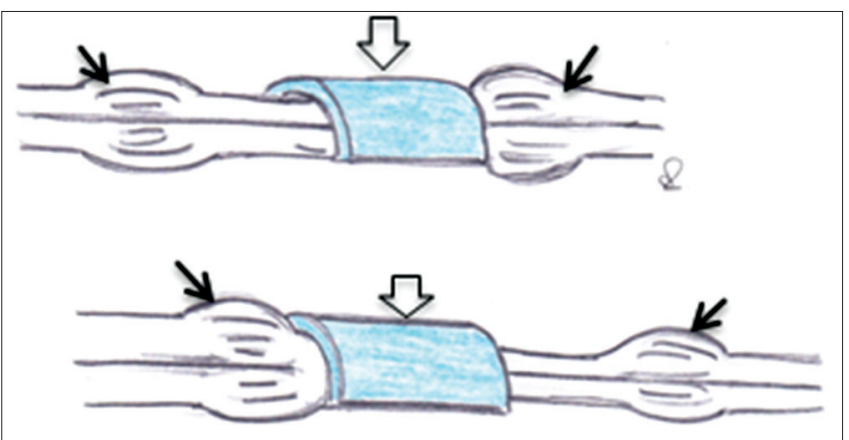

Figure 1: The A1 pulley thickens in response to synovitis and constricts the flexor tendons

\section{Check reins}

Treatment of proximal interphalangeal (PIP) joint contractures is often reported to be less than optimal. ${ }^{[8]}$ The volar plate at the PIP joint is a unique structure that prevents hyperextension at the PIP joint and absorbs enormous compression loads. The PIP volar plate is a thick, strong fibrocartilaginous structure, lined on the volar surface by peritendinous synovium of the fibro-osseous sheath and on the dorsal surface by joint synovium. These 2 layers of synovium lie on either side of the thin joint capsule at the lateral sides of the volar plate..$^{[9]}$ Inflammation of these two different synovial surfaces influence each other and produce the unusual abnormal collagen hypertrophy termed the checkrein ligaments. These do not exist in the normal state but are produced under the influence of this "synovial sandwich." When treating contractures of the PIP joints, one must release these pathological structures in order to increase the movement in the joint. Results of a study using this technique indicated full intraoperative extension in 110 of 115 joints, with 2 joints requiring a collateral ligament release. Three of the 115 digits required a second checkrein release after intraoperative gains were not maintained. ${ }^{[9]}$

\section{Peripheral arthritis}

Peripheral arthritis is secondary to synovial traction and inflammation. Osteophytes and abnormal cartilage build up on the joint periphery. It is hypothesized that the areas of synovial attachment are responsible for the synovitic influence on collagen and bone formation. With chronic synovial inflammation, the mechanical traction at the synovial attachment point may play a part but the inflamed synovium communicates with the bone collagen resulting in osteophyte formation. Resecting these bone areas along with excision of involved synovium results in clearing of the patient's symptoms and significantly extending joint longevity. This occurs without having altered joint mechanics at the time of surgery.

\section{Distal radioulnar joint}

This approach has been used in the treatment of arthritis in the distal radioulnar joint (DRUJ). The treatment of DRUJ degenerative arthritis following failure of conservative treatment such as splinting and antiinflammatory medication includes complete elimination of the arthritic joint, as popularized by Darrach, ${ }^{[10]}$ a hemiresection-interposition technique, ${ }^{[11]}$ the matched distal ulna resection ${ }^{[12]}$ or the Sauvé-Kapandji procedure, as well as ulnar head or total joint replacement. ${ }^{[13]}$ A modified DRUJ arthritis technique based on the concept of proximal to distal progression of degenerative joint disease at the DRUJ has been described $^{[14]}$ [Figure 2]. The proximal one-third to one-half of the articular surface is typically resected around the entire circumference of the joint. In one published study, all patients noted significant improvement in symptoms. ${ }^{[14]}$ One patient went on to have a matched ulna arthroplasty. In another report on results of 29 patients, 5 (17\%) had additional surgery 


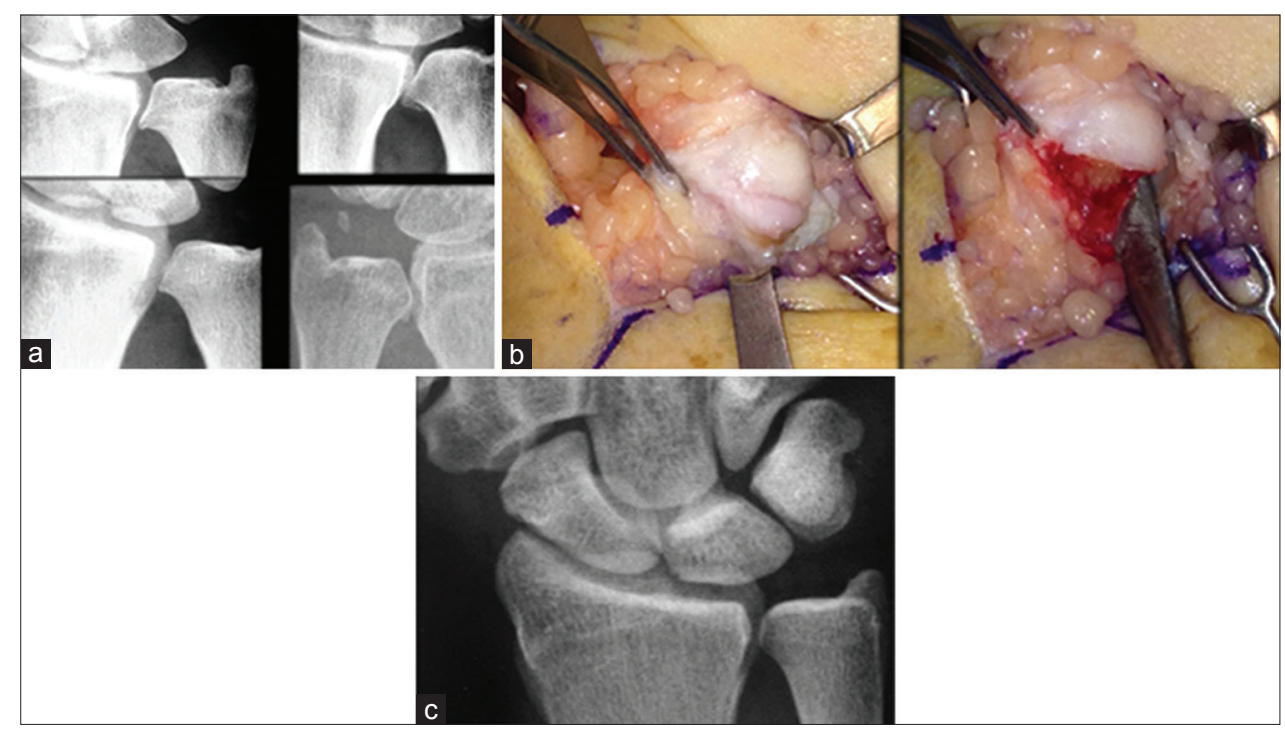

Figure 2: (a) Peripheral arthritis is an early stage of bone response to synovitis. In the DRUJ, it typically begins along the proximal joint where synovium attaches. It has the appearance of a "goatee" on the articular surface of the ulna as noted in these 4 symptomatic patients; (b) at surgery, the osteophyte is made up of soft reactive bone, which is easily removed circumferentially; (c) a 5-year postoperation follow-up shows no progression of DRUJ arthritis in this asymptomatic patient

after the DRUJ arthroplasty specific to the ulno-carpal/ DRUJ complex (four patients matched ulna arthroplasty, one patient triquetral impingement ligament tear [TILT] and ulna styloidectomy). ${ }^{[15]}$

\section{Dorsal wrist syndrome}

Another example of peripheral arthritis is the dorsal wrist syndrome (DWS). This common diagnosis of wrist pathology results from scaphoid instability after ligament tears, extreme loading of the wrist or a physiologically inadequate ligament system. The most common problem in the human wrist is the tendency for the proximal scaphoid pole to escape from beneath the capitate. Under load, this displacing scaphoid produces stretch and insult to the synovium. In its mildest form, acute wrist trauma produces scapholunate $(\mathrm{SL})$ synovitis and ligamentous strain without a SL ligament tear. A more substantial ligament tear may result in a displacing scaphoid accompanied by chronic synovitis. These wrists are painful and will not tolerate loading. Conservative treatment consists of splinting and other types of activity modification. ${ }^{[16]}$

Surgical management of DWS after 6 months of conservative care involves exploration of the SL joint with excision of the soft tissue synovial mass and any associated ganglia. Bony ridging and osteophytes form on the dorsum of the scaphoid and occasionally the lunate and are present in every case to some extent [Figure 3]. The dorsal ridging is believed to be the synovial attachment point responsible for molecular remodeling of collagen and bone due to the synovial inflammation. No change in scaphoid stability is accomplished. One hundred and fifty-one cases of surgically treated DWS were evaluated and $<10 \%$ of these wrists required subsequent scaphoid stabilization (scaphoid-trapezium-trapezoid (STT) fusion). Wollstein et al. ${ }^{[17]}$ presented results on 80 patients surgically treated for DWS, with $25 \%$ requiring some form of further surgery, including 9 STT fusions and 2 proximal
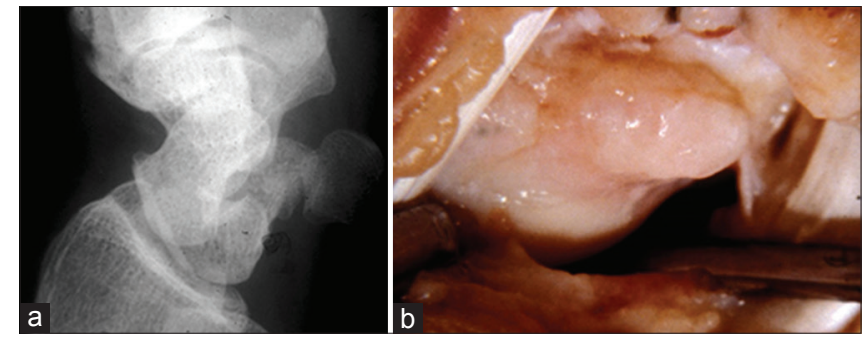

Figure 3: In dorsal wrist syndrome, the inflamed synovium produces peripheral osteophytes as noted on the dorsum of the scaphoid in this oblique X-ray (a) and at surgery (b)

row carpectomies. It is hypothesized that the resection of this synovitic attachment point is responsible for the relatively low rates of progression to arthritis despite continued abnormal scaphoid migration under load. A second group with a similar surgical procedure has been described with $86 \%$ of their patients having good to excellent results. ${ }^{[18]}$

In conclusion, inflamed synovium influences adjacent collagen. This fundamental relationship is the basis for many of the pathologic conditions of the hand, from capsular and ligament collagen to bone collagen (the "collasyn theory"). Viewing pathology of the hand in this manner may enhance our understanding and consequent treatment of hand conditions. The synovial cells produce a multitude of molecules and mediators involved in normal joint function as well as inflammatory mediators such as cytokines in response to osteoarthritis. ${ }^{[1,20]}$ Lubricin and hyaluronic acid are two important lubricant molecules produced by synovium. Recent evidence has shown that these molecules are important in articular cartilage maintenance and loss of these substances can lead to osteoarthritic degeneration. ${ }^{[21-23]}$ A reactive synovium produces factors related to inflammation through participation in multiple pathways. ${ }^{.24-27]}$ Synovium includes mesenchymal stem cells capable of differentiating into 
various tissue types including cartilage, muscle and bone. [28-30] Thus, synovium plays a key role in the repair of injured connective tissue components, but may also create the environment in which further pathology occurs. ${ }^{[19]}$

Further study in this area may allow us to understand and address this synovial influence before it exerts its effect on surrounding collagen.

\section{REFERENCES}

I. Moutet F. Flexor tendon pulley system: anatomy, pathology, treatment. Chir Main 2003;22:1-12.

2. Vuillemin V, Guerini H, Bard H, Morvan G. Stenosing tenosynovitis. J Ultrasound 20I2;I5:20-8

3. Tung WL, Kuo LC, Lai KY, Jou IM, Sun YN, Su FC. Quantitative evidence of kinematics and functional differences in different graded trigger fingers. Clin Biomech (Bristol, Avon) 2010;25:535-40.

4. Huisstede BM, Hoogvliet P, Coert JH, Fridén J, European HANDGUIDE Group. Multidisciplinary consensus guideline for managing trigger finger: results from the European HANDGUIDE Study. Phys Ther 2014;94: I 42I-33.

5. Mol MF, Neuhaus V, Becker SJ, Jupiter JB, Mudgal C, Ring D. Resolution and recurrence rates of idiopathic trigger finger after corticosteroid injection. Hand (N Y) 2013;8:183-90.

6. Zhou CL, Wang XT, Chi ZY, Yan JL. Extensor tendon injury due to repetitive wrist dorsiflexion: morphological study of extensor retinaculum and extensor tendon. Cell Biochem Biophys 2014;70:1 191-7.

7. DiFelice A Jr, Seiler JG 3rd, Whitesides TE Jr. The compartments of the hand: an anatomic study. J Hand Surg Am 1998;23:682-6.

8. Yang G, McGlinn EP, Chung KC. Management of the stiff finger: evidence and outcomes. Clin Plast Surg 2014;41:50I-I2.

9. Watson HK, Light TR, Johnson TR. Checkrein resection for flexion contracture of the middle joint. J Hand Surg Am 1979;4:67-7I.

10. Berg E. The Darrach procedure in rheumatoid arthritis. Clin Orthop Relat Res 1979; | 38:310-I.

II. Bowers WH. Distal radioulnar joint arthroplasty: the hemiresectioninterposition technique. J Hand Surg Am 1985; 10:169-78.

12. Watson HK, Ryu JY, Burgess RC. Matched distal ulnar resection. J Hand Surg Am 1986; 11:812-7.

13. Friedman SL, Palmer AK. The ulnar impaction syndrome. Hand Clin 1991;7:295-310.

14. Watson HK, Manzo RL. Modified arthroplasty of the distal radio-ulnar joint. J Hand Surg Br 2002;27:322-5.

15. Wollstein R, Watson HK, Phillips J, Clavijo J, Patel V, Carlson L. Ulnar sided wrist pain and distal radioulnar joint osteoarthritis; is surgical arthroplasty enough? Rheumatol Rep 2012;4:6-8.

16. Liao JC, Chong AK, Tan DM. Causes and assessment of subacute and chronic wrist pain. Singapore Med J 2013;54:592-7.

17. Wollstein R, Watson HK, Wear-Maggitti K, Schmidt S, Carlson L. Surgical technique for the treatment of radial wrist pain. Scand J Plast Reconstr Surg Hand Surg 2008;42:149-52.

18. Steinberg BD, Kleinman WB. Occult scapholunate ganglion: a cause of dorsal radial wrist pain. J Hand Surg Am 1999;24:225-3I.

19. Scanzello CR, Goldring SR. The role of synovitis in osteoarthritis pathogenesis. Bone 2012;51:249-57.

20. Gara SK, Grumati P, Urciuolo A, Bonaldo P, Kobbe B, Koch M, Paulsson M, Wagener R. Three novel collagen VI chains with high homology to the alpha3 chain. J Biol Chem 2008;283:10658-70.

21. Koyama E, Saunders C, Salhab I, Decker RS, Chen I, Um H, Pacifici M, $\mathrm{Nah}$ HD. Lubricin is required for the structural integrity and post-natal maintenance of TMJ. J Dent Res 2014;93:663-70.

22. Hill A, Duran J, Purcell P. Lubricin protects the temporomandibular joint surfaces from degeneration. PLoS One 2014;9:el06497.

23. Chang DP, Guilak F, Jay GD, Zauscher S. Interaction of lubricin with type II collagen surfaces: adsorption, friction, and normal forces. J Biomech 20। 4; 47:659-66.

24. Sakurada S, Kato T, Okamoto T. Induction of cytokines and ICAM-I by proinflammatory cytokines in primary rheumatoid synovial fibroblasts and inhibition by $\mathrm{N}$-acetyl-L-cysteine and aspirin. Int Immunol 1996;8: I483-93.

25. Sakurai S, Hayashi T, Iwasaki S, Kohno T, Kohno M. Expression of wnt signaling molecules in the synovial membranes of rabbit ankle joints injected with Enterococcus faecalis cell fractions. Mod Rheumatol 2003;13:35-43.

26. Miao CG, Yang YY, He X, Li XF, Huang C, Huang Y, Zhang L, Lv XW, Jin Y, Li J. Wnt signaling pathway in rheumatoid arthritis, with special emphasis on the different roles in synovial inflammation and bone remodeling. Cell Signal 20I3;25:2069-78.

27. Qin SS, Yu YX, Li QK, Yu ZW. Interaction of human synovial phospholipase A2 with mixed lipid bilayers: a coarse-grain and all-atom molecular dynamics simulation study. Biochemistry 2013;52:1477-89.

28. Chen XM, Xia J, Zhou T, Yuan Q, Zhang WF, Hu CP, Li YJ, Jiang JL. Involvement of DDAH/ADMA pathway in the pathogenesis of rheumatoid arthritis in rats. Int Immunopharmacol 2013;16:322-31.

29. Ozasa Y, Amadio PC, Thoreson AR, An KN, Zhao C. Repopulation of intrasynovial flexor tendon allograft with bone marrow stromal cells: an ex vivo model. Tissue Eng Part A 20।4;20:566-74.

30. Yang Z, Schmitt JF, Lee EH. Immunohistochemical analysis of human mesenchymal stem cells differentiating into chondrogenic, osteogenic, and adipogenic lineages. Methods Mol Biol 20I I;698:353-66.

How to cite this article: Watson $\mathrm{HK}$, Traverso $\mathrm{P}$, Carlson L, Mastella D, Wollstein R. Surgical treatment of synovial-collagen disorders of the hand. Plast Aesthet Res 2015;2:47-50.

Source of Support: Nil, Conflict of Interest: None declared.

Received: 16-10-2014; Accepted: 22-12-2014 